\title{
MACES IN UROLOGY
}

Arch. Esp. Urol. 2009; 62 (6): 508-509

\section{"FOURNIER GANGRENE"}

Alberto Hernández Castrillo, Enrique de Diego Rodríguez, Miguel Angel Rado Velázquez, Jose Manuel Lanzas Prieto and Jose Luis Conty Serrano'.

Department of Urology and General Urology. Hospital Comarcal de Laredo. Laredo. Sapin.

\section{$\Lambda$}

67 year old male with a medical history of alcoholic liver cirrhosis. Without any previous urological history.

Yesterday, the patient was seen in the Emergency Department for intense pain in the anal area that had progressed over one week which was being assessed by General Surgery and diagnosed as a possible anal fissure. The patient was prescribed topical nitroglycerin cream.

The patient again returned to the Emergency Department, this time for scrotal inflammation and pain which had progressed over 18 hours. Accompanied by dysuria. In Emergency, he presented a fever of $38^{\circ} \mathrm{C}$. The patient is catheterised, presenting 150 cc of urine with leucocyturia and bacteriuria. Haemogram: 18000 Leucocytes. Blood Chemistry: Normal.

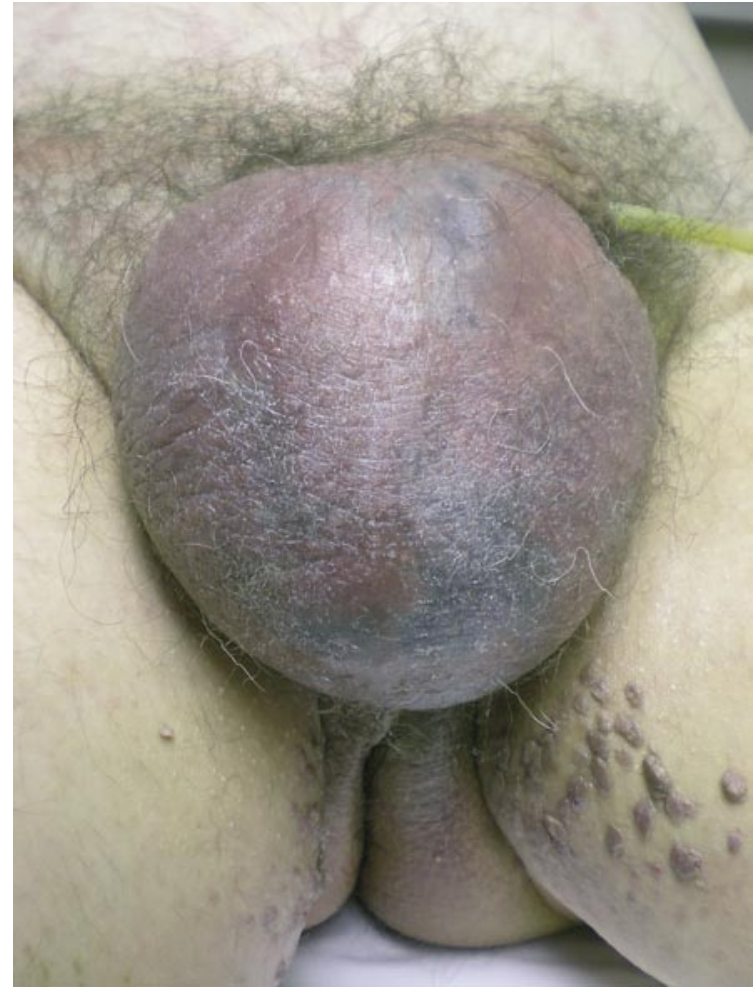

FIGURE 1. Bottom of the figure: Painful and inflamed scrotum with violet-coloured areas and crepitation. 
Upon physical examination, the patient presents painful inflammation of the left perineum and scrotum. The scrotum presents violet-coloured areas (Figure 1). Crepitation is observed upon palpation. Radiography was performed where air in the scrotum, dissecting towards the left groin could be clearly observed (Figure 2). Antibiotic treatment was ordered and emergency intervention was carried out (Figures 3, 4 and 5).

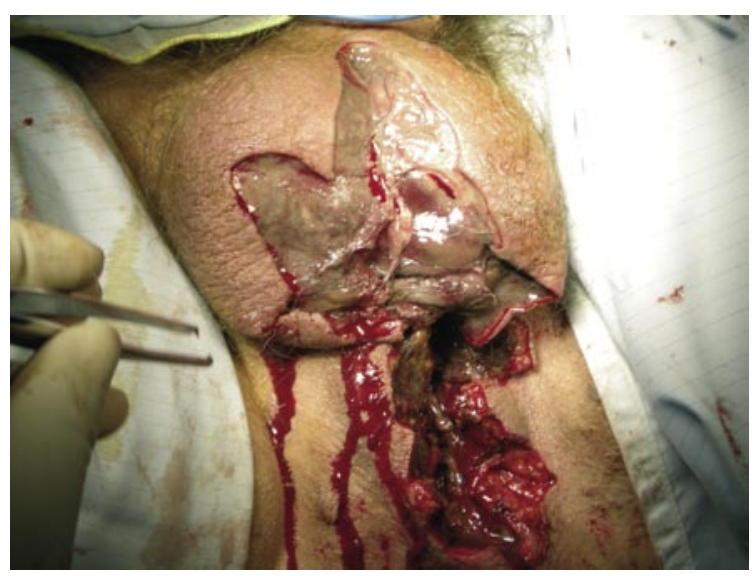

FIGURE 3. Bottom of the figure: Excision of necrotic tissues.

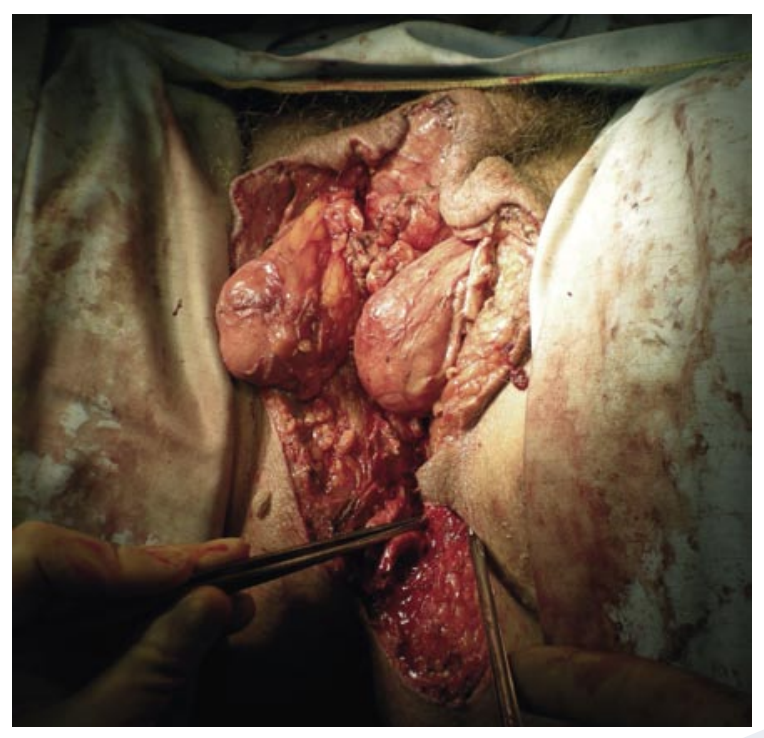

FIGURE 5. Bottom of the figure: Final results.

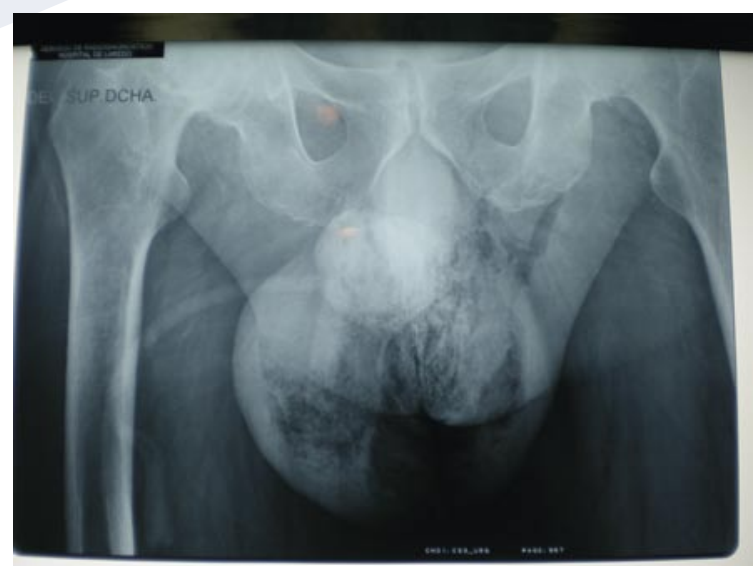

FIGURE 2. Bottom of the figure: Radiography in which air in the scrotum can be observed towards the left groin.

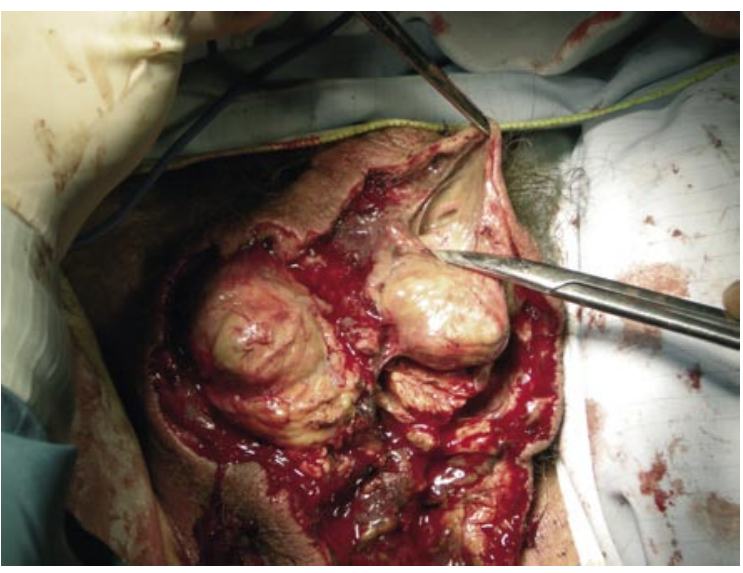

FIGURE 4. Bottom of the figure: Debridement.

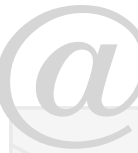

\section{CORRESPONDENCE}

Alberto Hernández Castrillo

Servicio de Urología

Hospital comarcal de Laredo.

Av./ Derechos Humanos s/n.

39770. Laredo. Cantabria. (Spain).

a.h.castrillo@telefonica.net

Accepted for publication: April 1st, 2008. 